\title{
Zenker's Diverticulum Suspected to be a Thyroid Nodule Diagnosed on Fine Needle Aspiration: A Case Report
}

\author{
Jeong Hoon Kima, Young Sik Choi ${ }^{\mathrm{b}, \mathrm{d}}$, Bu Kyung Kim ${ }^{\mathrm{b}}$, \\ Jun Seop Lee ${ }^{\mathrm{b}}$, Yo-Han Park ${ }^{\mathrm{b}}$, Bang Hur ${ }^{\mathrm{c}}$
}

\begin{abstract}
Zenker's diverticulum is mimicking thyroid nodule on ultrasonograhy (US). Therefore, it has risk of fine needle aspiration (FNA) on that lesion. There are only four case reports in the literature of fine needle aspiration of Zenker's diverticula masquerading as a thyroid nodule. We report a case of Zenker's dverticulitum suspected to be a thyroid nodule on US and performed US-guided FNA with examination of cytology in this patient. A 53-yr-old woman was referred to our center for FNA of a thyroid nodule. The thyroid US demonstrated a $1.3 \times 1.6 \mathrm{~cm}$, poorly-defined nodule containing multiple echogenic foci in the posterior medial aspect of the left thyroid. We performed US-guided FNA on that lesion. Papanicolaou stain showed squamous epithelial cells and numerous bacilli. We diagnosed this patient as having a Zenker's diverticulum, and this was confirmed by esophagram.
\end{abstract}

Keywords: Zenker's diverticulum; Fine needle aspiration; Thyroid nodule

\section{Introduction}

The Zenker's diverticulum is the most common diverticulum

Manuscript accepted for publication March 13, 2012

${ }^{a}$ Department of General Surgery, Kosin University College of Medicine, Busan, Korea

${ }^{\mathrm{b}}$ Department of Internal Medicine, Kosin University College of Medicine, Busan, Korea

${ }^{\mathrm{c}}$ Department of Pathology, Kosin University College of Medicine, Busan, Korea

${ }^{\mathrm{d}}$ Corresponding author: Young Sik Choi, Department of Internal Medicine, Kosin University College of Medicine, 34 Amnam- dong, Seo-gu, Busan, 602-702, Korea. Email: yschoi@kosinmed.or.kr

doi:10.4021/jmc635e of the esophagus [1]. It occurs at sites of anatomic weakness in the hypopharynx or in the cervical esophagus near the cricopharyngeus muscle [2]. It is usually detected incidentally by esophagography. As diagnostic techniques for thyroid cancer have become more sensitive, the incidence rates have continued to increase for thyroid cancer in Korean people [3]. Therefore, recently, thyroid ultrasonography (US) examination was widespread in health surveillance in Korea. Many cases of Zenker's diverticula have been detected because they appeared similar to a thyroid nodule on a US [48]. Some of Zenker's diverticula look like microcalcification on US. Therefore, it is important to be able to differentiate between Zenker's diverticula and malignant thyroid nodules. Fine needle aspiration (FNA) of the thyroid is the recommended diagnostic test in the initial evaluation of thyroid nodules. FNA of Zenker's diverticulum masquerading as a thyroid nodule has only been reported four times in the literature [9-12].

Recently, we experience a case of US guided FNA on

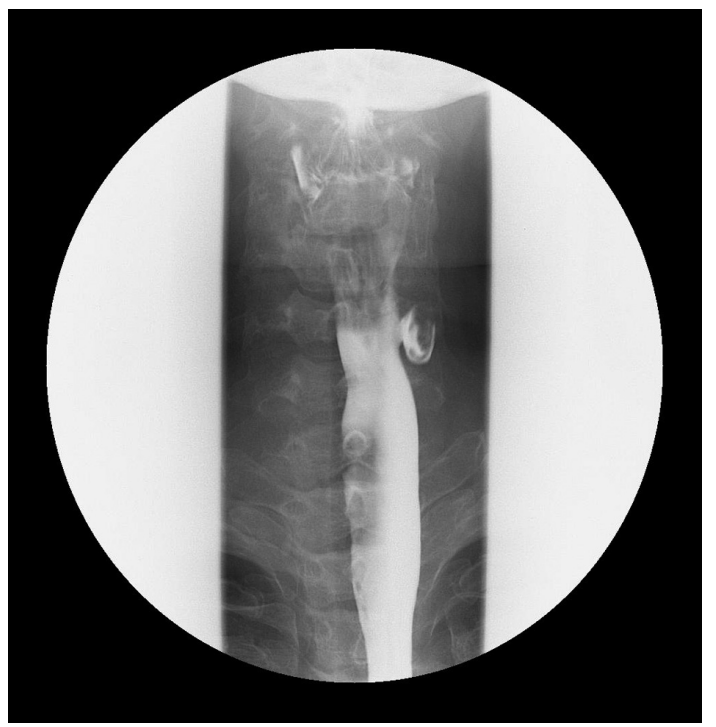

Figure 1. Ultrasonography of the neck. An oval-shape nodule, $1.3 \times 1.6 \mathrm{~cm}$, having a poorly-defined margin and multiple echogenic foci in the posterior medial aspect of the left thyroid lobe. 


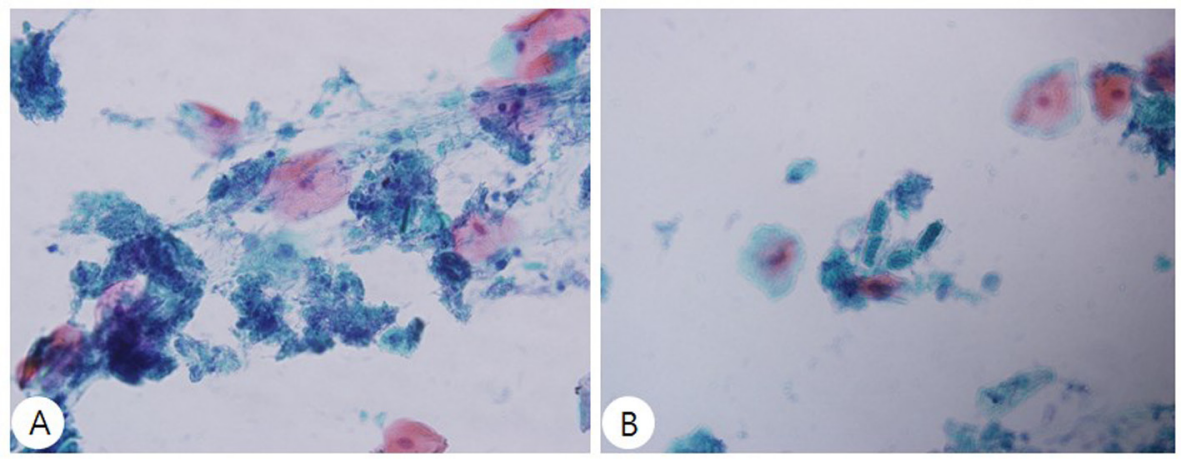

Figure 2. (A) Aspiration from the anterior neck region shows mature squamous epithelial cells with numerous bacilliform bacteria (Papanicolaou stain, $\times 400$ ). (B) A high-power view of a smear of the aspirate reveals some vegetable debris instead of thyroid tissue component (Papanicolaou stain, $\times 400$ ).

Zenker's dverticulum suspected to be a thyroid nodule.

\section{Case Report}

A 53-yr-old woman visited local medical clinic for her routine health checkup. On thyroid US, a nodule in the posterior medial aspect of left thyroid was detected incidentally. She was referred to our center for FNA of the thyroid nodule. She has no personal and family history of thyroid dysfunction and no specific medication history. Physical exam was normal.

US was carried out using a real time linear array $10 \mathrm{MHz}$ transducer. The thyroid US demonstrated a $1.3 \times 1.6 \mathrm{~cm}$, poorly-defined nodule containing multiple echogenic foci in the posterior medial aspect of the left thyroid (Fig. 1).

Before US-guided FNA, we asked the patient swallow three times. However, no shape change was observed. We then performed US guided FNA with 25-gauge without complication. Papanicolaou stain showed mature squamous epithelial cells with numerous bacilliform bacteria and some

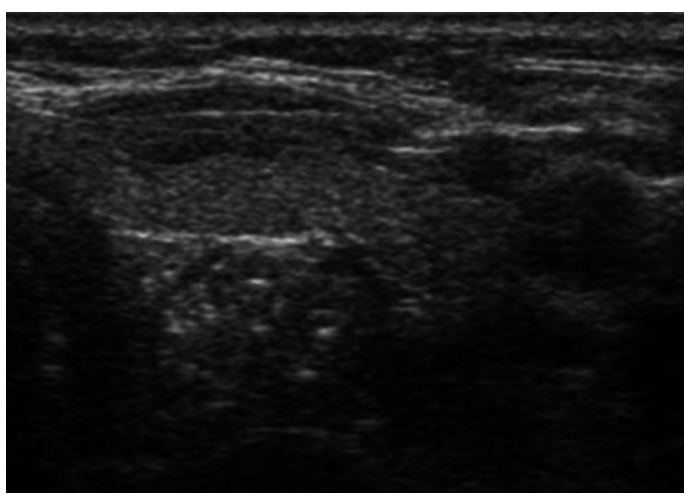

Figure 3. Esophagogram confirms a Zenker's dverticulum. The anteroposterior view of the neck shows the barium-retaining diverticulum. vegetable debris instead of thyroid tissue components (Fig. 2). These findings are not compatible with a thyroid lesion.

On the basis of the cytologic findings we suspected that this lesion was a Zenker's diverticulum. Subsequently, the patient underwent a barium swallow study that revealed 1.2 $\times 0.7 \mathrm{~cm}$ diverticulum in the left side of the cervical esophagus (Fig. 3). There was no complication from the FNA at the follow-up visit 1 month later.

\section{Discussion}

Zenker's diverticulum is an acquired pulsion diverticulum that results from posterior herniation of esophageal mucosa through a defect between the cricophyaryngeus and inferior pharyngeal constrictor muscles. The sonographic findings of Zenker's diverticula can be similar to those of thyroid nodules because the Zenker's diverticulum is also present at the thyroid level projecting toward the thyroid. Therefore, it is useful to know about the US findings of Zenker's diverticulum. Lixin et al. [8] proposed four types of US features of that are suggestive of a Zenker's diverticulum: 1) an isoechoic mass with a hypoechoic rim and internal small, punctuate, echogenic foci; 2) a mass containing a central hyperechoic area associated with a comet-tail artifact; 3) a hyperechoic and heterogeneous mass with stronger echoes anteriorly but no acoustic shadowing or reverberation artifacts; and 4) an oval-shaped mixed nodule with an unclear border and relatively multiple punctuate strong echoes. Our case showed oval-shaped mixed nodule, with unclear border and relatively multiple punctuate strong echoes. Furthermore, it had punctuate microcalcifications similar to those frequently seen in papillary thyroid cancer. Microcalcifications on US are useful for the diagnosis of malignant thyroid nodules $[13,14]$.

Walts el al. [9] also suggested clues that are helpful in establishing the diagnosis of Zenker's diverticulum by ultrasound include the following: 1 ) changes in sonogram elicited 
with emptying of the diverticulum by compression or by repositioning the patient during sonography, 2) presence of air fluid levels within the lesion, 3) movement of contents with swallowing, 4) changes in sonographic appearance of the lesion on repeat exam, 5) presence of a multilayered structure suggestive of digestive tract within the border of the nodule. Two previous cases of Zenker's diverticula diagnosed by ultrasonography had been observed in our center. The lesions of these two cases were located at the posterior medial aspect of the left lobe of the thyroid. This history led us to initially suspect Zenker's diverticulum in this case. We asked that the patient frequently swallow before US-guided FNA. However, no shape change was observed.

FNA of a Zenker's diverticulum initially thought to be a thyroid nodule has been very rarely reported [9-12]. Smears of FNA of Zenker's diverticulum contained combinations of mature squamous cells, associated bacteria (cocci and bacilli), and birefringent material. Our case also showed mature squamous epithelial cells with numerous bacilliform bacteria and some vegetable debris.

Currently, FNA of thyroid is most accurate and costeffective method for evaluating thyroid nodules and also is associated with minimal complications. However, before aspiration, the cytologist should be aware that Zenker's diverticulum may be initially misdiagnosed as thyroid nodule, especially when it located posterior medial aspect of the left thyroid gland.

\section{References}

1. Kumar A, Aggarwal S, Pham DH. Pharyngoesophageal (Zenker's) diverticulum mimicking thyroid nodule on ultrasonography: report of two cases. Journal of ultrasound in medicine : official journal of the American Institute of Ultrasound in Medicine. 1994;13(4):319-322.

2. Ekberg O, Nylander G. Lateral diverticula from the pharyngo-esophageal junction area. Radiology. 1983;146(1):117-122.

3. Jung KW, Park S, Kong HJ, Won YJ, Boo YK, Shin HR, Park EC, et al. Cancer statistics in Korea: incidence, mortality and survival in 2006-2007. Journal of Korean medical science. 2010;25(8):1113-1121.

4. Kwak JY, Kim EK. Sonographic findings of Zenker diverticula. Journal of ultrasound in medicine : official journal of the American Institute of Ultrasound in Medicine. 2006;25(5):639-642.

5. Kang HC. A case of Zenker's diverticulum masquerading as thyroid nodule. Korean J of Medicine. 2004;67: S757-760.

6. Komatsu M, Komatsu T, Inove K. Ultrasonography of Zenker's diverticulum: special reference to differential diagnosis from thyroid nodules. European journal of ultrasound : official journal of the European Federation of Societies for Ultrasound in Medicine and Biology. 2000;11(2):123-125.

7. Kim J, Kim YJ, Kim EK, Park CS. Incidentally found pharyngoesophageal diverticulum on ultrasonography. Yonsei medical journal. 2002;43(2):271-273.

8. Lixin J, Bing H, Zhigang W, Binghui Z. Sonographic diagnosis features of Zenker diverticulum. European journal of radiology. 2011;80(2):e13-19.

9. Walts AE, Braunstein G. Fine-needle aspiration of a paraesophageal diverticulum masquerading as a thyroid nodule. Diagnostic cytopathology. 2006;34(12):843845.

10. Shanker BA, Davidov T, Young J, Chang EI, Trooskin SZ. Zenker's diverticulum presenting as a thyroid nodule. Thyroid : official journal of the American Thyroid Association. 2010;20(4):439-440.

11. Rekhtman N, Rekhtman K, Sheth S, Ali SZ. A 62-yearold woman with a suspected thyroid nodule. Archives of pathology \& laboratory medicine. 2005;129(11):14971498 .

12. Oertel YC, Khedmati F, Bernanke AD. Esophageal diverticulum presenting as a thyroid nodule and diagnosed on fine-needle aspiration. Thyroid : official journal of the American Thyroid Association. 2009;19(10):11211123.

13. Papini E, Guglielmi R, Bianchini A, Crescenzi A, Taccogna S, Nardi F, Panunzi C, et al. Risk of malignancy in nonpalpable thyroid nodules: predictive value of ultrasound and color-Doppler features. The Journal of clinical endocrinology and metabolism. 2002;87(5):19411946.

14. Kim EK, Park CS, Chung WY, Oh KK, Kim DI, Lee JT, Yoo HS. New sonographic criteria for recommending fine-needle aspiration biopsy of nonpalpable solid nodules of the thyroid. AJR. American journal of roentgenology. 2002;178(3):687-691. 